SILVA BALBÉ, Paulo Valdemar da; BOFF, Salete Oro. O papel do estado e sua política fiscal em um modelo de desenvolvimento sustentável fundado nas garantias e liberdades individuais. Revista Eletrônica Direito e Política, Programa de Pós-Graduação Stricto Sensu em Ciência Jurídica da UNIVALI, Itajaí, v.10, n.3, $2^{\circ}$ quadrimestre de 2015. Disponível em: www.univali.br/direitoepolitica - ISSN 1980-7791

\title{
O PAPEL dO ESTADO E SUA POLÍtICA FISCAL EM UM MODELO DE DESENVOLVIMENTO SUSTENTÁVEL FUNDADO NAS GARANTIAS E LIBERDADES INDIVIDUAIS
}

THE ROLE OF THE STATE AND IT'S TAX POLICIES IN A SUSTAINABLE DEVELOPMENT MODEL FOUNDED IN WARRANTIES AND INDIVIDUAL FREEDOMS

\author{
Paulo Valdemar da Silva Balbé \\ Salete Oro Boff ${ }^{2}$
}

SUMÁRIO: Introdução; 1. Desenvolvimento sustentável: perspectivas diversas e complexidade na definição do termo; 2 . Desenvolvimento e sustentabilidade: do crescimento econômico ao estímulo das liberdades e capacidades individuais; 3. O papel do Estado na busca de um modelo de desenvolvimento sustentável fundado nas liberdades e capacidades individuais; 4. Tributação e desenvolvimento: o problema da justiça fiscal; 5. Progressividade e regressividade: o desafio de uma tributação justa; Considerações Finais; Referências das Fontes Citadas.

\section{RESUMO}

O presente artigo tem como objetivo analisar a relação entre tributação e desenvolvimento sustentável. Inicia com a descrição do processo histórico de construção do termo, seu uso pela Organização das Nações Unidas e a dificuldade de sua definição em decorrência da multiplicidade de fatores nele compreendidos. Destacam-se as concepções de crescimento econômico e de liberdade como possíveis condicionantes para o desenvolvimento. Na segunda parte do trabalho, desenvolve-se a ideia de insuficiência do Mercado como instrumento isolado para o desenvolvimento, com o consequente surgimento do Estado como importante árbitro e protagonista na correção de falhas de mercado e garantidor de bens e serviços públicos essenciais, com ênfase na atividade de tributação. O estudo segue com a identificação do sistema tributário e as

\footnotetext{
${ }^{1}$ Mestrando em Direito. Programa de Pós-Graduação Stricto Sensu. Faculdade Meridional (IMED). Vinculado ao grupo de pesquisa "Direito e desenvolvimento" pela Faculdade Meridional (IMED). Email: paulo.balbe@gmail.com

2 Pós-Doutora em Direito pela UFSC. Docente do PPGD IMED. Linha de pesquisa "Mecanismos defefetivação dos direitos fundamentais". Grupo de Estudo em Desenvolvimento, Inovação e Propriedade Intelectual - GEDIPI. E-mail salet.oro.boff@terra.com.br.
} 
SILVA BALBÉ, Paulo Valdemar da; BOFF, Salete Oro. O papel do estado e sua política fiscal em um modelo de desenvolvimento sustentável fundado nas garantias e liberdades individuais. Revista Eletrônica Direito e Política, Programa de Pós-Graduação Stricto Sensu em Ciência Jurídica da UNIVALI, Itajaí, v.10, n.3, $2^{\circ}$ quadrimestre de 2015. Disponível em: www.univali.br/direitoepolitica - ISSN 1980-7791

políticas fiscais como instrumentos relevantes para a garantia de condições necessárias para o desenvolvimento das liberdades individuais. Na quarta parte, estuda-se a progressividade e a regressividade dos tributos, destacando-se seus efeitos na política fiscal e, consequentemente, na liberdade dos indivíduos. 0 trabalho encerra com a confirmação da hipótese de que a política fiscal e a tributação podem caracterizar meios relevantes para o desenvolvimento das capacidades e liberdades individuais.

PALAVRAS-CHAVE: Desenvolvimento sustentável; tributo; política fiscal; regressividade; capacidade contributiva

\section{ABSTRACT}

The objective of this paper is to analyze the relationship between taxation and sustainable development. It starts with a description of the historical process of the construction of the term, its use by the United Nations Organization and the difficulty in defining the term that derives from the number of factors that it covers. The concepts of economic growth and of freedom stand out as possible requirements for development. In the second part of the paper the idea is developed of the insufficiency of the market as a sole instrument for development, and of the consequent growth of the role of the state as an important arbitrator and protagonist in the correction of market failings and guarantor of essential goods and public services, with an emphasis on the process of taxation. The study continues with the identification of the taxation system and financial policy as relevant instruments to guarantee the conditions necessary the development of individual liberty. The fourth part studies the progressivity and regressivity of taxation, with an emphasis on their effects on financial policy and, as a consequence, on the liberty of individuals. The paper concludes with the confirmation of the hypothesis the financial policy and taxation can be characterized as relevant means for the development of individual capacities and liberties.

KEYWORDS: Sustainable development; taxation; financial policy; regressivity; contributional capacity.

\section{INTRODUÇÃO}

Temas recorrentes nas pautas políticas globais, pelo menos nos últimos 40 (quarenta) anos, desenvolvimento e sustentabilidade são termos que continuam a despertar uma profunda inquietação na Ciência, em seus mais variados ramos. Os estudos são diversos, partindo de múltiplos problemas e hipóteses, não raro ocasionando disputas fundadas em paixões e ideologias. Não se exagera em afirmar que todos buscam o elemento mágico, a "pedra filosofal" capaz de 
SILVA BALBÉ, Paulo Valdemar da; BOFF, Salete Oro. O papel do estado e sua política fiscal em um modelo de desenvolvimento sustentável fundado nas garantias e liberdades individuais. Revista Eletrônica Direito e Política, Programa de Pós-Graduação Stricto Sensu em Ciência Jurídica da UNIVALI, Itajaí, v.10, n.3, $2^{\circ}$ quadrimestre de 2015. Disponível em: www.univali.br/direitoepolitica - ISSN 1980-7791

transmutar a incerteza em uma solução uniforme, um modelo de desenvolvimento sustentável digno de aplicação geral e cuja confiabilidade seja indiscutível.

Infelizmente esse anseio não é, nem o futuro garante que o seja, factível. Decorrência lógica de um tema tão amplo que admite em seu bojo uma considerável quantidade de problemas não passíveis de análises e soluções completas por ramos estanques do conhecimento humano.

O que se tem consciência é de que algo precisa ser feito, sobretudo em razão dos alarmantes indicadores de degradação ambiental e os indícios de que a escassez de elementos naturais possa estar relacionada às atividades do Homem. Surgem dessa preocupação global as primeiras tentativas de definição de "desenvolvimento sustentável", bem como de identificação de suas causas e possíveis soluções.

Desse processo surgiram inúmeras concepções, que podem ser sintetizadas, correndo o risco da generalização, em duas correntes de pensamento: a) uma compreensão crítica da sustentabilidade, cujos fautores são céticos em relação às soluções que possam ser alcançadas no atual estágio de compreensão humana com o uso do ferramental epistemológico tradicional. Advogam a necessidade de uma completa revolução do próprio conhecimento, mormente de seus paradigmas dominantes (por exemplo: a tecnociência e o método cartesiano) e, consequentemente, da relação homem com o meio. Denota-se de suas premissas um componente escatológico; b) uma noção "prática", menos exigente, posto que voltada ao implemento de soluções a curto e médio prazos, com utilização dos métodos e paradigmas atuais dos ramos da Ciência, ainda que combinados.

Essa última corrente tem preponderado nos diálogos político e científico. E é natural que assim o seja, porque o homem se apega às situações conhecidas e busca, por todos os modos, reduzir a realidade ao seu arcabouço cognitivo, recusando-se a acreditar na falibilidade de seus construtos teóricos, percepção bem retratada no poema de T.S. Eliot ${ }^{3}$ : "o gênero humano não pode suportar muita realidade."

\footnotetext{
${ }^{3}$ Burnt Norton in Quatro Quartetos. Tradução de Maria Amélia Neto. 3a. ed. Lisboa: Ática, 1983.
} 
SILVA BALBÉ, Paulo Valdemar da; BOFF, Salete Oro. O papel do estado e sua política fiscal em um modelo de desenvolvimento sustentável fundado nas garantias e liberdades individuais. Revista Eletrônica Direito e Política, Programa de Pós-Graduação Stricto Sensu em Ciência Jurídica da UNIVALI, Itajaí, v.10, n.3, $2^{\circ}$ quadrimestre de 2015. Disponível em: www.univali.br/direitoepolitica - ISSN 1980-7791

Surgem então soluções contingentes, não dissociadas completamente das condições históricas, porquanto relacionadas aos modelos político e econômico atuais. É esse o caso das discussões contemporâneas sobre a necessidade de "crescimento econômico" como condicionante para o desenvolvimento. Irrompem, entretanto, novas hipóteses, que embora não caracterizem uma ruptura no paradigma dominante, trazem para consideração novos fatores, alçando-os à qualidade de fim precípuo e sinônimo de desenvolvimento sustentável.

Decorrente desse processo de articulação e tensão entre os modelos tradicionais e a busca por parâmetros alternativos, as condições materiais, especialmente a riqueza, passam a ser consideradas singelos meios, instrumentos, voltados para o alcance de valores superiores, como a liberdade e as capacidades individuais. Essa mudança acaba levando a formular novas hipóteses para o alcance de um novo significado para "desenvolvimento sustentável", na qual o Mercado deixa de ser considerado o único instrumento hábil para essa finalidade.

Nesse paradigma o Estado também assume o papel protagonista, atuando na regulação do mercado e garantindo o atendimento às necessidades básicas dos indivíduos. E imerso no mesmo contexto desponta a política fiscal (e nesta contida a tributação) como uma das funções estatais usualmente (quando não sempre) utilizadas. Todavia, pode-se afirmar que o sistema tributário seja relevante para o desenvolvimento sustentável de um país? Caso positivo, de que modo poderia contribuir para um modelo de sustentabilidade?

Partindo de uma análise da relação entre desenvolvimento sustentável e tributação, a hipótese provável é que o sistema tributário, embora não possa ser alçado a uma condição isolada, influencia todo o plexo de relações entre Estado e cidadãos. Tem, portanto, íntima relação com o projeto de desenvolvimento e pode caracterizar um instrumento relevante para o desenvolvimento das capacidades e liberdades individuais.

Para a abordagem do tema será utilizado o método hipotético-dedutivo. No desenvolvimento do trabalho serão utilizados os procedimentos histórico e funcionalista, mediante revisão bibliográfica de livros e artigos relacionados ao objeto do estudo. 
SILVA BALBÉ, Paulo Valdemar da; BOFF, Salete Oro. O papel do estado e sua política fiscal em um modelo de desenvolvimento sustentável fundado nas garantias e liberdades individuais. Revista Eletrônica Direito e Política, Programa de Pós-Graduação Stricto Sensu em Ciência Jurídica da UNIVALI, Itajaí, v.10, n.3, $2^{\circ}$ quadrimestre de 2015. Disponível em: www.univali.br/direitoepolitica - ISSN 1980-7791

\section{DesenVolvimento SUStentável: Perspectivas diversas e COMPLEXIDADE NA DEFINIÇÃO DO TERMO}

A expressão "desenvolvimento sustentável" ainda é vinculada a uma concepção econômica, que não abrange de forma bastante compreensiva os fenômenos relacionados à degradação do ambiente e à crescente escassez dos recursos naturais. Antes, procura interpretá-los restritivamente, como fenômenos relacionados a alguns poucos fatores.

Contudo, a compreensão do significado de "sustentabilidade" é tarefa por demais complexa para que seja levada a cabo mediante uso de visões restritivas de um único ramo da Ciência, pois "[...] a sua multidimensionalidade e complexidade explicam o seu caráter fugidio" ${ }^{4}$. Logo, por abranger a análise e relação de fenômenos biológicos, físicos e humanos, pressupõe uma amplitude de hipóteses, o que inviabiliza, por ora, sua redução a um "conceito" puro.

Possível que sejam utilizadas tentativas de definições, especialmente aquelas já consagradas nos documentos internacionais como, por exemplo, no "Relatório Bruntland", da Organização das Nações Unidas, mas de igual forma não se afastam de relacionar a expressão "desenvolvimento sustentável" com vários fatores de ordem social, econômica e política. Nesse aspecto cabe pontuar a nítida conotação política da expressão, que fora cunhada muito mais com o propósito de angariar atenção e fomentar o interesse da comunidade internacional na discussão daquele tema ${ }^{5}$.

Sob a perspectiva ambiental ou ecológica, a incerteza do conteúdo semântico do termo "desenvolvimento sustentável" se deve em grande parte às dificuldades das ciências naturais em compreender o complexo sistema de relações entre os elementos do meio ambiente (causas, consequências), o que inviabiliza aferir com precisão a medida do impacto dos danos ambientais e a individualização de seus agentes causadores.

\footnotetext{
${ }^{4}$ SACHS, Ignacy. Desenvolvimento: includente, sustentável, sustentado. Rio de Janeiro: Garamond, 2008, p. 25.

${ }^{5}$ VEIGA, José Eli da. A desgovernança mundial da sustentabilidade. São Paulo: Editora 34, 2013, p. 164 e 191.
} 
SILVA BALBÉ, Paulo Valdemar da; BOFF, Salete Oro. O papel do estado e sua política fiscal em um modelo de desenvolvimento sustentável fundado nas garantias e liberdades individuais. Revista Eletrônica Direito e Política, Programa de Pós-Graduação Stricto Sensu em Ciência Jurídica da UNIVALI, Itajaí, v.10, n.3, $2^{\circ}$ quadrimestre de 2015. Disponível em: www.univali.br/direitoepolitica - ISSN 1980-7791

O problema da definição do que seja "sustentabilidade" é exposto por Veiga da seguinte forma:

\begin{abstract}
Sendo uma questão primordialmente ética, só se pode louvar o fato da idéia de sustentabilidade ter adquirido tanta importância nos últimos vinte anos, mesmo que ela não possa ser entendida como um conceito científico. A sustentabilidade não é, e nunca será, uma noção de natureza precisa, discreta, analítica ou aritmética, como qualquer positivista gostaria que fosse ${ }^{6}$.
\end{abstract}

Nesse contexto de pluralidade de significados e de fraca compreensão da interação entre a atuação do homem e o meio ambiente, a percepção dominante é a de que existe o risco de degradação, mas esse risco, dependendo da ótica adotada, poderá ser subvalorizado. Tem sido essa a opção da doutrina econômica clássica, que confia na superação da probabilidade de extinção dos recursos naturais mediante o progresso da tecnologia, ou seja, resultante do processo de crescimento econômico. De outro lado, os mais céticos, não tão fascinados com a promessa tecnológica, preferem apostar na redução do crescimento e do consumo, na expectativa de alcance de uma condição estacionária 7 .

$\mathrm{Na}$ ótica dos economistas neoclássicos, que não se deixam contaminar pela euforia das promessas tecnológicas, a solução adotada para minimizar a degradação ambiental tem sido a de incluir os recursos naturais dentro da lógica de mercado, atribuindo-Ihes preços condizentes com sua escassez ou, então, inserindo-Ihes em novos mercados mediante mecanismos de compensações e trocas de cotas de poluição ${ }^{8}$.

Sistemática semelhante é adotada pelos órgãos incumbidos da regulação do mercado ao exigirem que os danos ambientais causados sejam de alguma forma "internalizados", refletindo no preço dos produtos. Entretanto, a "precificação" somente se aplica àqueles recursos naturais passíveis de apropriação e produção

\footnotetext{
6 Ibid., p. 165.

7 Ibid., p. 111-123.

${ }^{8}$ Ibid., p. 124-126.
} 
SILVA BALBÉ, Paulo Valdemar da; BOFF, Salete Oro. O papel do estado e sua política fiscal em um modelo de desenvolvimento sustentável fundado nas garantias e liberdades individuais. Revista Eletrônica Direito e Política, Programa de Pós-Graduação Stricto Sensu em Ciência Jurídica da UNIVALI, Itajaí, v.10, n.3, $2^{\circ}$ quadrimestre de 2015. Disponível em: www.univali.br/direitoepolitica - ISSN 1980-7791

pelo homem, os quais correspondem a uma parcela pouco expressiva do ambiente $^{9}$. Pode-se acrescer que esse tipo de solução só é válida em um curto período de tempo, pois não impede a degradação, apenas a retarda.

Nada obstante o cômputo da utilização dos recursos naturais, a atribuição de um preço elevado, corresponda a uma solução que, isoladamente, não se presta a servir de empecilho à degradação, pode constituir um ponto relevante para incutir maior racionalidade no consumo. Poder-se-ia afirmar, de certo modo, que o valor de um produto no mercado seja reflexo de sua escassez, situação que desestimularia sua aquisição.

Mas existe também uma outra perspectiva para o desenvolvimento sustentável, não exclusivamente econômica. Poderia estar relacionada ao desenvolvimento das liberdades individuais e à satisfação de outras necessidades humanas, nem sempre relacionadas à capacidade de adquirir bens e serviços, mas condizentes com a satisfação de necessidades básicas. Partindo da ideia de que o estado é o principal agente atuante para o suprimento dessas necessidades, importa que seja dotado de recursos suficientes para custear instituições básicas essenciais para o alcance desse objetivo.

Percebe-se claramente que dentre tantas outras dimensões da problemática do desenvolvimento despontam com destaque pelo menos duas: 1) a preservação dos elementos do ambiente natural; 2) a superação das barreiras que impedem as melhorias na qualidade de vida dos indivíduos da espécie humana, proporcionando meios para que sejam alcançadas condições favoráveis a um processo de decrescimento, com a consequente redução do consumo e dos recursos naturais.

Em ambas as situações o sistema tributário caracteriza-se por ser um mecanismo apto para contribuir para o desenvolvimento sustentável. O presente estudo restringe a análise sobre a relação entre tributação e sua contribuição para um modelo de desenvolvimento sustentável cuja premissa seja o fortalecimento das liberdades substanciais.

Impõe-se, todavia, a necessidade de se traçar um breve relato do gradual processo de mudança de perspectivas que levaram à concepção desse modelo.

\footnotetext{
${ }^{9}$ Ibid., p. $126-127$.
} 
SILVA BALBÉ, Paulo Valdemar da; BOFF, Salete Oro. O papel do estado e sua política fiscal em um modelo de desenvolvimento sustentável fundado nas garantias e liberdades individuais. Revista Eletrônica Direito e Política, Programa de Pós-Graduação Stricto Sensu em Ciência Jurídica da UNIVALI, Itajaí, v.10, n.3, $2^{\circ}$ quadrimestre de 2015. Disponível em: www.univali.br/direitoepolitica - ISSN 1980-7791

\section{DESENVOLVIMENTO E SUSTENTABILIDADE: DO CRESCIMENTO ECONÔMICO AO ESTÍMULO DAS LIBERDADES E CAPACIDADES INDIVIDUAIS}

Desenvolvimento e sustentabilidade são termos que, sob a perspectiva econômica, sempre foram convergentes. Isso porque sob a ótica restritiva das doutrinas econômicas clássicas, tornar um desenvolvimento sustentável equivale a Ihe propiciar condições para que o "desenvolvimento" evolua constantemente, ou seja, para que sejam mantidas as condições necessárias para um crescimento econômico ${ }^{10}$.

O termo "desenvolvimento sustentável" passou, gradualmente, a ter seus significados questionados a partir da década de 70, com a divulgação dos primeiros relatos científicos que relacionaram os processos do modelo econômico preponderante (capitalismo-industrialização-crescimento econômico) com a degradação do ambiente. Nesse sentido merece destaque o famoso estudo elaborado pelo "Clube de Roma", no ano de 1972, e a "Primeira Conferência Mundial sobre o Homem e o Meio Ambiente" patrocinada pela Organização das Nações Unidas - ONU, naquele mesmo ano.

Desde então o tema "desenvolvimento sustentável" tem ocupado a pauta de deliberações dos Estados-Nação pelo menos nos últimos quarenta anos. Nesses acordos multilaterais torna-se aparente a relação, sobretudo as tentativas de conciliação, entre o desenvolvimento sustentável e o crescimento econômico

Sem abdicar do paradigma capitalista/industrial, uma das hipóteses formuladas para se atingir uma "sustentabilidade" foi a eliminação da pobreza, acreditando que sua redução, sobretudo nos países periféricos do cenário econômico mundial (designados eufemisticamente os países integrantes do 'terceiro mundo', ou os países em 'desenvolvimento') seria a solução ideal para que fossem superados os problemas de degradação ambiental.

Partindo dessa convicção a Organização das Nações Unidas, desde o ano de 1972, tem tratado o tema do subdesenvolvimento e a pobreza como

\footnotetext{
${ }^{10}$ Ibid., p. 17.
} 
SILVA BALBÉ, Paulo Valdemar da; BOFF, Salete Oro. O papel do estado e sua política fiscal em um modelo de desenvolvimento sustentável fundado nas garantias e liberdades individuais. Revista Eletrônica Direito e Política, Programa de Pós-Graduação Stricto Sensu em Ciência Jurídica da UNIVALI, Itajaí, v.10, n.3, $2^{\circ}$ quadrimestre de 2015. Disponível em: www.univali.br/direitoepolitica - ISSN 1980-7791

intrinsecamente relacionados ${ }^{11}$. A pobreza seria superada, então, com o crescimento da economia, viabilizando a repartição efetiva dos ganhos econômicos. A pujança, o crescimento, se encarregariam de criar as condições, no próprio mercado, para que os países pobres modificassem essa condição ${ }^{12}$.

As desigualdades, portanto, seriam solucionadas com crescimento e aumento da riqueza, sem necessidade de se repensar o contexto econômico global e a estrutura de mercado. Embora a desigualdade tenha sido o foco do contexto político ${ }^{13}$, não foram criadas hipóteses alternativas para sua eliminação ou redução.

A ideia de "crescimento econômico", como fator preponderante para o desenvolvimento sustentável, passou a ser questionada, considerando que o alcance desse patamar por alguns Estados não acarretou a diminuição da pobreza e a redução da desigualdade entre países centrais e periféricos. Veiga ilustra essa afirmação de forma interessante:

A primeira contribuição significativa sobre essa relação surgiu em célebre conferência presidencial proferida por Simon Kuznets (1901-1985) [...] Na citada conferência, Kuznets procurou demonstrar que a desigualdade de renda tendia a aumentar na fase inicial da industrialização de um país, ocorrendo o inverso em fase posterior, quando esse país estivesse desenvolvido. Foi essa a base científica daquela famosa parábola que insistia na necessidade de que primeiro o bolo crescesse para que depois fosse repartido [...] A rigor, ela só foi realmente colocada em xeque quarenta anos depois, quando o Banco Mundial terminou a montagem de uma base de dados envolvendo 108 economias nacionais durante quatro décadas. Essencialmente porque mostrou a inexistência de um único padrão histórico de evolução da distribuição de renda ${ }^{14}$.

${ }^{11}$ Organização das Nações Unidas (ONU). Declaration of the United Nations Conference on the Human Environment, 1972.

12 VEIGA, José Eli da. Op. cit. p. 35.

${ }^{13}$ Organização das Nações Unidas (ONU). Our common future. World Commission on Environment Development, 1987. Conhecida pelo apelido de "Relatório Bruntland".

14 VEIGA, José Eli da. Op. cit. p. 43-44. 
SILVA BALBÉ, Paulo Valdemar da; BOFF, Salete Oro. O papel do estado e sua política fiscal em um modelo de desenvolvimento sustentável fundado nas garantias e liberdades individuais. Revista Eletrônica Direito e Política, Programa de Pós-Graduação Stricto Sensu em Ciência Jurídica da UNIVALI, Itajaí, v.10, n.3, $2^{\circ}$ quadrimestre de 2015. Disponível em: www.univali.br/direitoepolitica - ISSN 1980-7791

Ainda sob a perspectiva de desenvolvimento econômico (com utilização do Produto Interno Bruto - PIB como referencial), surgiram teorias (a exemplo dos estudos de Giovanni Arrighi e Celso Furtado) de que o desenvolvimento de países emergentes, também chamados de "periféricos", muito dificilmente conseguiriam atingir patamares que se aproximassem dos países mais ricos. Nessa ótica, o desenvolvimento foi visto como uma "quimera" ou um "mito"15.

O ponto de virada teve início mais tarde quando o Programa das Nações Unidas (PNUD) instituiu o "Índice de Desenvolvimento Humano" (IDH), no ano de 1990, como critério alternativo para a aferição do desenvolvimento de um Estado, descolando-o do viés predominantemente econômico do "Produto Interno Bruto" (PIB). Despontou uma nova perspectiva que deu ensejo ao questionamento de novos significados para o termo "desenvolvimento sustentável"

Superada a ideia de crescimento econômico (ou majoração do PIB) como fator condicionante para a repartição dos ganhos econômicos e, consequentemente, para redução da pobreza e da desigualdade, a concepção atual é a de que o desenvolvimento sustentável deve estar aliado a um processo mais complexo, mormente relacionado com a quebra do paradigma epistemológico que condiciona o estudo da Economia a uma metodologia exclusivamente empírica ${ }^{16}$. Parte-se da premissa de que desenvolvimento de um Estado também decorre de um processo cultural e pode ser alcançado pelo estímulo da criatividade ${ }^{17}$ de seus indivíduos ${ }^{18}$. A criatividade, por conseguinte, depende de um conjunto básico de instituições que garantam aos cidadãos o exercício de suas liberdades substanciais, viabilizando realizar suas escolhas de acordo com seus valores ${ }^{19}$.

A garantia de instituições básicas que assegurem o efetivo exercício da liberdade individual e o consequente desenvolvimento das capacidades é, em síntese,

\footnotetext{
${ }^{15}$ Ibid. p. 20-23.

16 Ibid., p. 49.

17 Entendida aqui a criatividade como capacidade intelectual, científica, na criação de novos métodos, processos, técnicas. O desempenho criativo de um ofício ou profissão, contribuindo para a criação de produtos com maior valor agregado.

18 VEIGA, José Eli da. Op. cit., p. 54.

${ }^{19}$ SEN, Amartya. A ideia de justiça. Tradução Denise Bottmann e Ricardo Donidelli Mendes. São Paulo: Companhia das Letras, 2011, p. 265.
} 
SILVA BALBÉ, Paulo Valdemar da; BOFF, Salete Oro. O papel do estado e sua política fiscal em um modelo de desenvolvimento sustentável fundado nas garantias e liberdades individuais. Revista Eletrônica Direito e Política, Programa de Pós-Graduação Stricto Sensu em Ciência Jurídica da UNIVALI, Itajaí, v.10, n.3, $2^{\circ}$ quadrimestre de 2015. Disponível em: www.univali.br/direitoepolitica - ISSN 1980-7791

resultado de um processo político ${ }^{20}$, porquanto no campo das deliberações democráticas reside o espaço de criação e ajuste das estruturas formais e serviços públicos necessários para o desenvolvimento das capacidades e, consequentemente, o alcance da liberdade.

E é com base nessa nova ótica, nessa nova concepção de desenvolvimento (entendido como o exercício pleno das capacidades e liberdades individuais), que deve ser avaliado o papel do Estado Moderno.

\section{O PAPEL DO ESTADO NA BUSCA DE UM MODELO DE DESENVOLVIMENTO SUSTENTÁVEL FUNDADO NAS LIBERDADES E CAPACIDADES INDIVIDUAIS.}

Atribuir ao mercado a condição de único protagonista para a solução de problemas atinentes ao esgotamento de recursos naturais não é uma medida prudente, tendo em conta que, como já exposto, a "precificação" dos recursos em consonância com sua escassez somente alcança uma pequena gama de elementos que compõem a biosfera.

Episódios recentes vieram confirmar que a crença na auto-regulação do mercado é inocente, pois a racionalidade empregada, destinada ao alcance de produtividade ótima (e maximização do lucro) deixa à margem inúmeros interesses gerais e, portanto, olvida o conteúdo ético. Nesse sentido Freitas esclarece que

De maneira incontendível, a desregulação estatal revelou-se aposta ruinosa na resiliência infalível dos mercados [...] A suposta resiliência de mercado revelou-se uma falácia autoevidente, que produz enormes estragos sistêmicos ${ }^{21}$

Observado esse contexto, não é demais postular a importância de um modelo que, sem descurar dos problemas sociais, proporcione condições para a economia de mercado. Busca-se com essa fórmula compatibilizar a ideologia

\footnotetext{
${ }^{20}$ VEIGA, José Eli da. Op. cit., p. 77.

${ }^{21}$ FREITAS, Juarez. Sustentabilidade: direito ao futuro. Belo Horizonte: Fórum, 2011, p. 255.
} 
SILVA BALBÉ, Paulo Valdemar da; BOFF, Salete Oro. O papel do estado e sua política fiscal em um modelo de desenvolvimento sustentável fundado nas garantias e liberdades individuais. Revista Eletrônica Direito e Política, Programa de Pós-Graduação Stricto Sensu em Ciência Jurídica da UNIVALI, Itajaí, v.10, n.3, $2^{\circ}$ quadrimestre de 2015. Disponível em: www.univali.br/direitoepolitica - ISSN 1980-7791

liberal econômica (ou neoliberal) e os anseios sociais. Nesse processo, o papel do Estado é tão relevante quanto o do mercado.

A norma é o fundamento de validade do Estado Moderno no contexto de um modelo liberal ${ }^{22}$ democrático, e sua origem decorre da soberania popular. Logo, ainda que se abra espaço aos mercados, estipulando-se um plexo de garantias imprescindíveis às relações de trocas e à satisfação dos interesses individuais, o próprio Direito restringe o alcance do mercado quando se propõe a tutelar uma gama de interesses relevantes para toda a coletividade.

O Estado, nesse contexto, adquire importância, proporcionando balizas regulatórias para proteção dos recursos não passíveis de utilização nos processos produtivos (apropriação, precificação, trocas comerciais). E essa atividade estatal ocorre mediante a edição e aplicação de um complexo sistema de normas relacionadas - fruto de prévios debates e da deliberação pública de representantes eleitos pelo povo - sobre os assuntos considerados relevantes pelas esferas políticas formais. Nesse sentido a observação de Kaul, Grunbert e Stern:

Num contexto nacional a solução para as falhas de mercado e os problemas da ação coletiva é, com frequência, trazer o Estado para melhorar as condições de cooperação, entre outros modos, estabelecendo novos ou mais claros direitos de propriedade, determinando normas e padrões ou proporcionando incentivos fiscais. Em alguns casos o poder coercitivo do governo produz ótimos resultados socialmente. Em muitas outras instâncias o Estado desempenha um papel catalítico essencial. Não obstante, a oferta de bens públicos também sofre de falhas estatais, tais como a busca de rentabilidade por parte dos criadores de políticas e burocratas, as parcialidades no gasto público em favor de segmentos influentes da população ou os impasses políticos entre grupos de interesse concorrentes ${ }^{23}$.

\footnotetext{
22 Adota-se aqui o termo "liberal" sob uma concepção ampla, nas palavras de Bobbio, Matteucci e Pasquino: "[...] o único denominador comum entre posições tão diferentes consiste ha defesa do Estado liberal, nascido antes de o termo liberal entrar no uso político: um Estado tem a finalidade de garantir os direitos do indivíduo contra o poder político e, para atingir esta finalidade, exige formas, mais ou menos amplas, de representação política." (1998, p. 690).

${ }^{23}$ KAUL, Inge; GRUNBERG, Isabelle; STERN, Marc A. Bens públicos globais. Tradução de Zaida Maldonado. Rio de Janeiro: Record, 2012, p. 47.
} 
SILVA BALBÉ, Paulo Valdemar da; BOFF, Salete Oro. O papel do estado e sua política fiscal em um modelo de desenvolvimento sustentável fundado nas garantias e liberdades individuais. Revista Eletrônica Direito e Política, Programa de Pós-Graduação Stricto Sensu em Ciência Jurídica da UNIVALI, Itajaí, v.10, n.3, $2^{\circ}$ quadrimestre de 2015. Disponível em: www.univali.br/direitoepolitica - ISSN 1980-7791

Presente esse objetivo e delimitado o papel do Estado, existem mecanismos aptos a serem utilizados para a proteção desses interesses: a) a atividade regulatória; b) o poder de polícia e c) a tributação. O uso desses mecanismos pode ser eficaz para a correção de falhas de mercado, em especial as externalidades negativas e, dentre estas, a degradação ambiental.

A atividade regulatória é essencial para o desenvolvimento de um ambiente de mercado que proporcione segurança, não somente aos investidores, mas também aos próprios usuários dos serviços. Por atuar na estipulação e defesa de regras, de standarts de atuação, pode ser um veículo relevante para a imposição de padrões de conduta que visem o respeito do ambiente natural ${ }^{24}$.

Basta que se observe o conjunto de atividades de mercado hoje sujeitas à atividade regulatória para que se compreenda sua importância para o alcance de objetivos desvinculados da maximização do lucro. Por exemplo: uma norma que estipule a redução de gases tóxicos resultantes da combustão de veículos automotores atua como fator importante para a indústria automobilística aumentar a eficiência dos veículos à combustão interna ou arriscar-se na pesquisa e desenvolvimento de novas tecnologias.

São evidentes as dificuldades presentes na atividade regulatória, sobretudo nos Estados nos quais não há efetiva consolidação da democracia ${ }^{25}$, nos quais está presente o interesse político de exercer o domínio pela imposição de interesses transitórios do grupo dominante, usualmente travestido de controle hierárquico formal, mas destituído de validade, porquanto em desconformidade com a legislação de regência.

Ainda quando existentes instâncias e órgãos instituídos consoante 0 ordenamento jurídico, essa situação de interferência está presente. Veja-se, por exemplo, a problemática da autonomia das agências reguladoras, cuja atuação consoante os princípios democráticos depende de condições para o desempenho

24 GIAMBIAGI, Fábio; ALÉM, Ana Cláudia. Finanças públicas: teoria e prática no Brasil. 4a. edição. Rio de Janeiro: Elsevier, 2011, p. 07.

25 Entendido esse processo como a situação de confusão entre a atividade estatal administrativa/burocrática, com atuação pautada pela lei. 
SILVA BALBÉ, Paulo Valdemar da; BOFF, Salete Oro. O papel do estado e sua política fiscal em um modelo de desenvolvimento sustentável fundado nas garantias e liberdades individuais. Revista Eletrônica Direito e Política, Programa de Pós-Graduação Stricto Sensu em Ciência Jurídica da UNIVALI, Itajaí, v.10, n.3, $2^{\circ}$ quadrimestre de 2015. Disponível em: www.univali.br/direitoepolitica - ISSN 1980-7791

imparcial de seus misteres como, por exemplo, a necessidade de independência de seus dirigentes ${ }^{26}$.

Vista a questão sob um viés mais abrangente, é perceptível que as falhas do sistema regulatório não são atribuíveis exclusivamente ao Estado, considerando que os órgãos incumbidos de regular os serviços públicos enfrentam dificuldades como a assimetria de informações ${ }^{27}$ e captura ${ }^{28}$, decorrentes da fragilidade de suas estruturas ${ }^{29}$.

Sem prejuízo das dificuldades acima apontadas, inerentes à realidade, resulta que ainda assim a atividade regulatória pode configurar importante mecanismo para a proteção do meio ambiente e a construção de um modelo de desenvolvimento sustentável. Nesse sentido Freitas pontua que

[...] o conceito de regulação estatal pode, com vantagens, ser compreendido como inerência do reconceituado 'poder de polícia administrativa', desde que adotado o devido acordo semântico, no bojo da renovação geral do Direito Administrativo. Nesse aspecto, o que mais importa é compreender que, no século em curso, o Direito Administrativo, a despeito de preocupantes sinais contraditórios, precisa se converter, em larga medida, no Direito da Administração Sustentável, sem prejuízo da indeclinável tarefa prestacional de assegurar o núcleo essencial dos serviços públicos [...] A pouco e pouco, com o necessário redesenho institucional, começará a ceder o executivismo hipostasiado (mormente no presidencialismo, que se caracteriza pela concentração unipessoal das chefias de Estado e governo). Com efeito, o Direito Administrativo emite sinais - ainda tímidos, é verdade - de se encaminhar para o papel de concretizador imparcial das políticas públicas da sustentabilidade, que transcendem os mandatos. Nesse ponto, porém, sobreleva a valorização das atividades típicas

${ }^{26}$ GIAMBIAGI, Fábio; ALÉM, Ana Cláudia. Op. cit., p. 415.

27 Entendida como a dificuldade de compreensão dos recursos e procedimentos técnicos utilizados pelas empresas submetidas à regulação, o que exige a necessidade de contratação de um quadro especializado e permanente, composto por especialistas na área.

${ }^{28}$ Consistente no risco de o órgão regulador, composto por uma gama de especialistas vinculados à área de atuação técnica das empresas submetidas à regulação, passar a ratificar os procedimentos adotados, afastando-se de sua incumbência precípua de realizar um controle imparcial.

${ }^{29}$ GIAMBIAGI, Fábio; ALÉM, Ana Cláudia. Op. cit., p. 415. 
SILVA BALBÉ, Paulo Valdemar da; BOFF, Salete Oro. O papel do estado e sua política fiscal em um modelo de desenvolvimento sustentável fundado nas garantias e liberdades individuais. Revista Eletrônica Direito e Política, Programa de Pós-Graduação Stricto Sensu em Ciência Jurídica da UNIVALI, Itajaí, v.10, n.3, $2^{\circ}$ quadrimestre de 2015. Disponível em: www.univali.br/direitoepolitica - ISSN 1980-7791

de Estado, aquelas que permanecem quando os governos passam $^{30}$.

O poder de polícia é outro espectro da atuação estatal que reforça a atividade regulatória - relacionada aos serviços de utilidade pública - e amplia a eficácia das normas editadas mediante a fiscalização de outras atividades exercidas pelos demais indivíduos no mercado, com a possibilidade de imposição de sanções pecuniárias. Para o desempenho dessas atividades são criados órgãos e serviços públicos, inclusive para atuação em situações concretas onde presentes violações à legislação, inclusive relacionadas com a proteção do ambiente.

Em razão de seu campo de aplicação ser mais abrangente, pois voltado à fiscalização das atividades exercidas pelos sujeitos sem a necessária qualidade de concessionários de serviços públicos ou prestadores de serviços essenciais, caracteriza-se por ser a atividade estatal mais presente no cotidiano do cidadão comum, porquanto seu exercício implica na restrição de direitos e liberdades. É o que ocorre, na seara ambiental, quando a) se exigem prévias licenças para a exploração de serviços e a construção de obras com probabilidade de causarem reflexos danos à natureza ${ }^{31}$; b) são embargadas ou interditadas obras; c) são suspensas atividades danosas ${ }^{32}$.

A violação do patrimônio ambiental admite graus de intensidade, sobretudo tomando em consideração a extensão do dano e a inviabilidade de reparação em um curto lapso temporal, o que viabiliza, em determinadas circunstâncias, que a sanção aplicada seja substancialmente mais rigorosa, a ponto de interferir na liberdade do poluidor. Nesses casos o Estado atua como titular da tutela penal.

Também a atuação do Estado para resguardo do meio ambiente pode ocorrer sob a perspectiva da política fiscal, mediante a instituição de tributos vinculados a atividades potencialmente danosas ou, ainda, pela criação de hipóteses normativas que possibilitem a redução da carga tributária em decorrência de

\footnotetext{
${ }^{30}$ FREITAS, Juarez. Sustentabilidade: direito ao futuro. Belo Horizonte: Fórum, 2011, p. 256257.

31 Vide artigo 90, III, da Lei no 6.938/81

32 Vide artigo 14, IV, da Lei no $6.938 / 81$
} 
SILVA BALBÉ, Paulo Valdemar da; BOFF, Salete Oro. O papel do estado e sua política fiscal em um modelo de desenvolvimento sustentável fundado nas garantias e liberdades individuais. Revista Eletrônica Direito e Política, Programa de Pós-Graduação Stricto Sensu em Ciência Jurídica da UNIVALI, Itajaí, v.10, n.3, $2^{\circ}$ quadrimestre de 2015. Disponível em: www.univali.br/direitoepolitica - ISSN 1980-7791

determinados comportamentos dos contribuintes consonantes com as diretrizes de proteção ambiental.

Mas um ponto que usualmente passa despercebido é a relação da política fiscal e da tributação com o processo de construção de um modelo de desenvolvimento sustentável que ultrapassa o singelo papel de mecanismos indutores da preservação ambiental. Pressupondo que também o desenvolvimento das liberdades individuais tenha um papel relevante, senão decisivo, os mecanismos fiscais também tem uma função a desempenhar nesse novo contexto.

Usualmente os tributos são utilizados com o propósito específico de atuar na função alocativa do Estado, garantindo recursos necessários ao custeio de serviços públicos essenciais, notadamente aqueles relacionados ao atendimento dos direitos fundamentais previstos na Constituição, pois esses bens trazem altos benefícios sociais e contribuem para os propósitos de desenvolvimento social previstos nos programas de governo.

Na desincumbência da função alocativa, o tributo adquire papel imprescindível, proporcionando que todos os demais procedimentos e mecanismos estatais possam contar com uma fonte de custeio. Nesse aspecto é sempre útil rememorar que a própria atividade estatal não se distancia do mercado e se utiliza de institutos que Ihe são peculiares, a exemplo do uso de mão-de-obra remunerada e da propriedade dos meios de produção ${ }^{33}$. Vale-se, portanto, dos próprios fundamentos do capitalismo para o funcionamento de seu aparato burocrático (mão-de-obra remunerada, aquisição de bens de produção), considerando que lhe é vedada a requisição de bens de seus súditos e a imposição de trabalho gratuito.

Resulta dessa circunstância a necessidade de buscar recursos no patrimônio de seus súditos, nas condições previstas nos instrumentos resultantes do exercício da soberania popular, ou seja, a lei. E a razão de ser de seu conteúdo normativo/impositivo resulta da ideia de que os indivíduos tem a tendência de se

\footnotetext{
${ }^{33}$ É com base nessas características que Weber sustenta a racionalidade da burocracia no Estado Moderno (WEBER, Max. Economia e sociedade: fundamentos da sociologia compreensiva. Volume II. Tradução Regis Barbosa e Karen Elsabe Barbosa. São Paulo: Editora UNB, 1999.). Essas situações pressupõem disponibilidades financeiras do Estado e sua participação nas relações de troca. Nesse sentido basta que se rememore os usuais contratos celebrados entre o Estado e terceiros (indivíduos, empresas) para a aquisição de bens e contratação de serviços.
} 
SILVA BALBÉ, Paulo Valdemar da; BOFF, Salete Oro. O papel do estado e sua política fiscal em um modelo de desenvolvimento sustentável fundado nas garantias e liberdades individuais. Revista Eletrônica Direito e Política, Programa de Pós-Graduação Stricto Sensu em Ciência Jurídica da UNIVALI, Itajaí, v.10, n.3, $2^{\circ}$ quadrimestre de 2015. Disponível em: www.univali.br/direitoepolitica - ISSN 1980-7791

esquivar do pagamento de determinados encargos resultantes de bens e serviços compartilhados ${ }^{34}$, comportamento já constatado nos estudos sociais complexos ${ }^{35}$. Constata-se, portanto, que a atuação do Estado ocorre sob vários aspectos, criando condições e estabelecendo balizas normativas do plexo de relações existentes na sociedade. Tais interferências são imprescindíveis para o resguardo das garantias e liberdades individuais e, sobretudo, para o equilíbrio de forças dentro do mercado.

Ademais, a política fiscal, pode ser instrumento eficaz para o estabelecimento de condições de justiça e redistribuição de recursos financeiros, contribuindo para a credibilidade no Estado e nas suas instituições.

\section{TRIBUTAÇÃO E DESENVOLVIMENTO: O PROBLEMA DA JUSTIÇA FISCAL}

Se adotada a premissa de que é razoável a imposição de encargos pecuniários para o custeio de bens e serviços públicos, eventuais objeções por parte dos cidadãos para a satisfação de obrigações dessa natureza deveriam estar restritas à uniformidade de sua exigência e ao grau de comprometimento do patrimônio pessoal.

A riqueza material, consubstanciada nos recursos financeiros, é revestida de grande importância em uma sociedade capitalista, pois garante o ingresso do indivíduo no mundo das trocas, permitindo que nele se alcance a situação de igualdade, pelo menos sob uma perspectiva formal.

Não constitui um fim, entretanto, mas um meio, dentre outros tantos, para a busca de um valor maior, que é a felicidade. Nesse contexto não há argumentos que possam sustentar o fato de que um indivíduo, por mais bem aquinhoado ou dotado de recursos materiais, possa efetivamente realizar todas as suas aspirações em um mundo desprovido de segurança, de condições básicas de higiene e de um mínimo de liberdade de expressão.

\footnotetext{
34 Vide o 'problema do carona" exposto nas formulações teóricas da matemática aplicada.

35 GIAMBIAGI, Fábio; ALÉM, Ana Cláudia. Finanças públicas: teoria e prática no Brasil. $4^{a}$. edição. Rio de Janeiro: Elsevier, 2011, p. 12.
} 
SILVA BALBÉ, Paulo Valdemar da; BOFF, Salete Oro. O papel do estado e sua política fiscal em um modelo de desenvolvimento sustentável fundado nas garantias e liberdades individuais. Revista Eletrônica Direito e Política, Programa de Pós-Graduação Stricto Sensu em Ciência Jurídica da UNIVALI, Itajaí, v.10, n.3, $2^{\circ}$ quadrimestre de 2015. Disponível em: www.univali.br/direitoepolitica - ISSN 1980-7791

Ser livre para poder realizar suas aspirações, para fazer aquilo que se valoriza, é ser dotado de capacidade, que consiste no poder de realizar atos e tomar as decisões (escolhas) em relação àquilo que se tem razão para valorizar. Nesse sentido Sen aponta que

[...] A idéia da capacidade pode acomodar essa importante distinção, uma vez que é orientada para a liberdade e as oportunidades, ou seja, a aptidão real das pessoas para escolher viver diferentes tipos de vida a seu alcance, em vez de confinar a atenção apenas ao que pode ser descrito como a culminação - ou consequências - da escolha ${ }^{36}$.

A importância social de uma tributação justa (com respeito às diferenças e consoante o critério de isonomia material) consiste na sua relação com três funções estatais específicas: a alocativa, a redistributiva e a terceira, não explorada pela doutrina convencional, de catalisadora do processo de legitimação do Estado e de suas instituições. As duas primeiras, incumbidas do custeio de serviços públicos essenciais (saneamento, saúde, segurança, previdência) e proteção social a indivíduos em situação de risco (renda mínima). A terceira como vetor de justiça e participação equânime.

A política fiscal é um fator essencial para o alcance do desenvolvimento sustentável, pois é uma ferramenta de ordenação das relações jurídicas celebradas pelos cidadãos no espaço territorial dos Estados que também pode ser direcionada para a redução das desigualdades econômicas, especialmente mediante a instituição de novos mecanismos que proporcionem a redução da carga tributária para as camadas sociais com menor disponibilidade de renda.

Nada obstante a criação de um sistema tributário tenha originariamente o escopo de cumprir com a função alocativa do Estado, proporcionando recursos necessários ao custeio de suas atividades essenciais, torna-se difícil, senão impossível, sob o conceito de Estado Moderno de bem-estar social, sustentar que a tributação esteja completamente desvinculada de uma função redistributiva, ou

\footnotetext{
${ }^{36}$ SEN, Amartya. A ideia de justiça. Tradução Denise Bottmann e Ricardo Donidelli Mendes. São Paulo: Companhia das Letras, 2011, p. 271.
} 
SILVA BALBÉ, Paulo Valdemar da; BOFF, Salete Oro. O papel do estado e sua política fiscal em um modelo de desenvolvimento sustentável fundado nas garantias e liberdades individuais. Revista Eletrônica Direito e Política, Programa de Pós-Graduação Stricto Sensu em Ciência Jurídica da UNIVALI, Itajaí, v.10, n.3, $2^{\circ}$ quadrimestre de 2015. Disponível em: www.univali.br/direitoepolitica - ISSN 1980-7791

seja, voltada à redução das desigualdades. Essa tem sido, entretanto, a posição defendida por parte da doutrina no ramo do Direito Tributário brasileiro ${ }^{37}$.

Acerca da possibilidade de uma função redistributiva na política fiscal é pertinente a transcrição do entendimento de Rawls:

Por fim, temos o sector de distribuição. Sua função é preservar uma justiça aproximada nas parcelas distributivas por meio da tributação e dos ajustes necessários ao direito de propriedade. Podemos distinguir dois aspectos desse sector. Em primeiro lugar, ele impõe vários impostos sobre heranças e doações e estabelece restrições ao direito de herança. A finalidade desses tributos e normas não é aumentar a receita (liberar recursos para o governo), mas corrigir, gradual e continuamente, a distribuição da riqueza e impedir concentrações de poder que prejudiquem o valor equitativo da liberdade política e da igualdade equitativa de oportunidades. Por exemplo, o princípio da tributação progressiva poderia ser aplicado aos beneficiários. Isso incentivaria uma ampla dispersão da propriedade que é, ao que parece, uma condição necessária à manutenção do valor equitativo das liberdades iguais. A herança desigual de riquezas não é em si mesma, mais injusta que a herança desigual de inteligência. É verdade que é mais fácil sujeitar a primeira ao controle social; mas o essencial é que, na medida do possível, as desigualdades que se fundamentam em ambas satisfaçam o princípio da diferença. Assim, a herança é permissível, contanto que as desigualdades resultantes tragam vantagens para os menos afortunados e sejam compatíveis com a liberdade equitativa de oportunidades ${ }^{38}$.

Sem descartar a hipótese da instituição de novas matrizes tributárias alternativa que, a depender da situação peculiar de cada Estado pode caracterizar grandes níveis de complexidade - é necessário que as políticas fiscais já aplicadas observem critérios justos para repartição aos seus cidadãos dos ônus resultantes da imposição tributária. Esses critérios devem ser utilizados no âmbito interno de cada sistema tributário, proporcionando-lhe coerência e,

\footnotetext{
37 TORRES, Heleno Taveira (org). Direito tributário ambiental. São Paulo: Malheiros, 2005, p. 26.

${ }^{38}$ RAWLS, John. Uma teoria da justiça. Tradução de Jussara Simões. São Paulo: Martins Fontes, 2008, p. 345-346.
} 
SILVA BALBÉ, Paulo Valdemar da; BOFF, Salete Oro. O papel do estado e sua política fiscal em um modelo de desenvolvimento sustentável fundado nas garantias e liberdades individuais. Revista Eletrônica Direito e Política, Programa de Pós-Graduação Stricto Sensu em Ciência Jurídica da UNIVALI, Itajaí, v.10, n.3, $2^{\circ}$ quadrimestre de 2015. Disponível em: www.univali.br/direitoepolitica - ISSN 1980-7791

consequentemente, legitimidade. Nesse sentido, argumenta Rawls que "O senso de justiça nos leva a promover esquemas justos e a fazer a nossa parte neles quando acreditamos que os outros, ou pelo menos um número suficiente deles, também farão a sua". ${ }^{39}$

A observância de critérios justos para o rateio dos ônus fiscais tem relação com a possibilidade de se instituirem melhores condições para o exercício das capacidades e liberdades individuais ( $\mathrm{e}$, consequentemente, para o desenvolvimento sustentável), pois incrementa a possibilidade de acesso dos extratos sociais menos favorecidos aos bens e serviços e reforça a legitimidade do Estado e de suas instituições, que passam a ser vistos como resultado de um processo democrático, fruto da participação política de seus súditos, e não como uma estrutura alheia, isolada das circunstâncias e problemas sociais.

Vale dizer que o tributo, ainda que não dotado de característica extrafiscal, deve observar critérios mínimos de justiça na distribuição dos encargos de sorte a respeitar a capacidade contributiva de cada cidadão, impedindo dessa forma a redução da capacidade econômica das camadas sociais com baixa renda. Decorre dessa constatação a importância da progressividade como técnica de tributação para o alcance de uma repartição justa da carga tributária.

\section{PROGRESSIVIDADE E REgRESSIVIDADE: O DESAFIO DE UMA TRIBUTAÇÃO JUSTA}

A progressividade é uma qualidade de algumas espécies de obrigações tributárias nas quais se opta por aumentar o valor dos tributos à medida em que é majorada a renda e o patrimônio do cidadão. Aplica-se, usualmente, aos tributos denominados diretos, ou seja, aqueles nos quais o pagamento do valor do tributo se esgota em uma única etapa, resultante da imposição do tributo ao cidadão, ou seja, encerra-se com o pagamento da obrigação sem repercutir em etapas posteriores.

Nos tributos diretos a aferição do valor do montante da obrigação tributária pode ou não estar relacionada à apreciação de fatores inerentes a aspectos pessoais

\footnotetext{
${ }^{39}$ Ibid., p. 333.
} 
SILVA BALBÉ, Paulo Valdemar da; BOFF, Salete Oro. O papel do estado e sua política fiscal em um modelo de desenvolvimento sustentável fundado nas garantias e liberdades individuais. Revista Eletrônica Direito e Política, Programa de Pós-Graduação Stricto Sensu em Ciência Jurídica da UNIVALI, Itajaí, v.10, n.3, $2^{\circ}$ quadrimestre de 2015. Disponível em: www.univali.br/direitoepolitica - ISSN 1980-7791

do próprio contribuinte. Se considerada sua condição pessoal será possível uma aferição muito aproximada da sua capacidade contributiva, viabilizando que seu ônus seja compatível com sua riqueza.

Nesses casos (tributos diretos e pessoais), o ajuste do impacto fiscal sob seu patrimônio poderá aproximar-se de uma condição ótima, dependendo de como o arcabouço normativo the permitirá deduzir seus gastos relacionados a condições essenciais à sua sobrevivência. É a regra dos impostos que incidem sobre a base econômica renda. É o ideal de uma tributação justa.

Em relação aos impostos reais, essa adequação às condições pessoais do contribuinte encontra-se em um grau menos preciso, pois leva-se em consideração para a imposição fiscal aspectos relacionados exclusivamente ao próprio bem, com base na suposição de que as características de determinados elementos patrimoniais possa refletir, indiretamente, a capacidade contributiva de seu titular. O ônus fiscal oscila de acordo com o valor do bem e outros aspectos a ele relativos.

Em um Estado cujas diretrizes normativas estejam voltadas para o atendimento de direitos fundamentais dos cidadãos, o custeio de serviços básicos como saúde, educação, moradia e alimentação deveriam necessariamente ser deduzidos da base imponível dos impostos pessoais (por exemplo, a renda).

A realidade, contudo, é diversa. As economias locais dos países periféricos, dependentes que são do capital externo, exigem alto ingresso de receitas públicas para o pagamento de juros a rentistas, condição para o ingresso e a manutenção de capital estrangeiro ${ }^{40}$ (SACHS, 2008, p. 21). Essa situação, aliada ao gasto público necessário para a manutenção do aparato administrativo do estado e o custeio de serviços públicos essenciais (sem prejuízo das políticas públicas de distribuição de renda), exige um considerável acréscimo de valores nos cofres públicos. ${ }^{41}$

40 SACHS, Ignacy. Desenvolvimento: includente, sustentável, sustentado. Rio de Janeiro: Garamond, 2008, p. 21.

${ }^{41}$ Merece destaque o fato de que o incentivo a uma base larga de tributação, com o intento de promover a arrecadação com maior ônus nos impostos indiretos e redução da progressividade nos impostos diretos, é fruto das propostas sintetizadas no "Consenso de Washington", cujas conclusões passaram a pautar todos os futuros pactos de financiamento pleiteados pelos países da América Latina perante o Fundo Monetário Internacional e demais agências internacionais 
SILVA BALBÉ, Paulo Valdemar da; BOFF, Salete Oro. O papel do estado e sua política fiscal em um modelo de desenvolvimento sustentável fundado nas garantias e liberdades individuais. Revista Eletrônica Direito e Política, Programa de Pós-Graduação Stricto Sensu em Ciência Jurídica da UNIVALI, Itajaí, v.10, n.3, $2^{\circ}$ quadrimestre de 2015. Disponível em: www.univali.br/direitoepolitica - ISSN 1980-7791

Resulta que, dessa necessidade crescente de disponibilidades financeiras, a política fiscal impõe que sejam pouco desenvolvidos ou desconsiderados critérios imprescindíveis para o adequado cálculo da capacidade contributiva dos cidadãos. Atende-se, por outro lado, uma exigência de simplificação dos mecanismos de tributação, obstando que seja valorada uma gama de elementos particulares de difícil conferência pelo Estado.

O velho "problema do carona" impõe uma lógica de controle que pretenda ser imune às falhas de fiscalização, reduzindo as perspectivas de uma apuração da capacidade contributiva em consonância com a realidade. Esse binômio "necessidade crescente de recursos financeiros + simplificação dos mecanismos de tributação" resulta em uma carga tributária desigual, injusta, pois desconsidera a parte da renda despendida pelos cidadãos para o custeio de serviços essenciais minimamente dignos, até então viáveis a serem prestados pelo Estado.

Em uma simplificação, é possível afirmar que a descaracterização do critério pessoal para a aferição do ônus tributário acarreta uma situação injusta: os recursos financeiros dos cidadãos, já comprometidos no cotidiano com o pagamento bens e serviços necessários para condições dignas de vida, não é desconsiderado pelo Estado e passa a servir de base imponível para a tributação sobre a renda. Em decorrência do caráter injusto dessa sistemática alguns países europeus, a exemplo da Alemanha e Espanha, já passaram a admitir a dedução de valores correspondentes aos gastos mínimos essenciais da base econômica dos tributos incidentes sobre a renda ${ }^{42}$.

A questão da injustiça e da desigualdade, entretanto, é mais evidente nos casos de tributação regressiva, ou seja, quando o indivíduo passa a ser onerado com maior ônus à medida em que sua capacidade de contribuição diminui. Nesses casos, não se instituem mecanismos hábeis para distinção entre contribuintes, porquanto são colocados sob uma condição de isonomia formal, ou seja, como

(DUTRA, Micaela Dominguez. Capacidade contributiva: análise dos direitos humanos e fundamentais. São Paulo: Saraiva, 2010, p. 56).

42 DUTRA, Micaela Dominguez. Capacidade contributiva: análise dos direitos humanos e fundamentais. São Paulo: Saraiva, 2010, p. 104-106. 
SILVA BALBÉ, Paulo Valdemar da; BOFF, Salete Oro. O papel do estado e sua política fiscal em um modelo de desenvolvimento sustentável fundado nas garantias e liberdades individuais. Revista Eletrônica Direito e Política, Programa de Pós-Graduação Stricto Sensu em Ciência Jurídica da UNIVALI, Itajaí, v.10, n.3, $2^{\circ}$ quadrimestre de 2015. Disponível em: www.univali.br/direitoepolitica - ISSN 1980-7791

participantes dotados de idênticas capacidades nas relações de troca ocorrentes no mercado. É o caso dos tributos decorrentes das relações de consumo.

Nos tributos indiretos, o cálculo do ônus fiscal incide sobre uma base econômica que, apesar de relacionada a um fato praticado pelo contribuinte, seu ônus é transferido para terceiros de modo uniforme, sem preocupação com a capacidade contributiva dos destinatários finais. Pelas características dos atos tributados, o valor do tributo passa a ser agregado no preço do produto. É o que ocorre no caso da tributação incidente sobre a cadeia produtiva de bens e serviços, na qual o elo final (consumidor) sofre todo o custo acumulado da imposição fiscal.

Taxar o consumo é medida que caracteriza opção política, considerando que a ocorrência ou não de maior incidência da carga tributária sobre o destinatário final dependerá da utilização simultânea de outros mecanismos como, por exemplo, a seletividade. Nesse contexto é possível que o consumo de bens luxuosos seja onerado com maior rigor, caso se pretenda o custeio de uma política de emprego mínimo e redução de importações ${ }^{43}$.

No caso brasileiro, as políticas públicas tem se destacado pelo implemento de medidas concretas voltadas para a diminuição da carga tributária e do próprio valor dos bens e serviços essenciais para indivíduos em condição de pobreza e extrema pobreza ${ }^{44}$. Utiliza-se um critério de seletividade para a diminuição do ônus fiscal e dos valores dos serviços.

Ainda que se pretenda utilizar o mecanismo da seletividade, o consumo realizado pela população de baixa renda continua sendo o mais onerado ${ }^{45}$, considerando a inúmera gama de bens e serviços cuja incidência do imposto não sofre redução,

43 SACHS, Ignacy. Desenvolvimento: includente, sustentável, sustentado. Rio de Janeiro: Garamond, 2008, p. 18.

44 Vide "Tarifa social de energia" prevista nas Leis no 10.438/2002 e 12.212/2010; "Telefone Popular", instituído pela Resolução ANATEL no 586, de 05/04/2012

45 Considerada a distribuição da carga tributária por faixa de renda, apurou-se que para os indivíduos com renda de até $\mathrm{R} \$ 120,00$ a carga tributária no Brasil corresponde ao percentual de $22,99 \%$ de sua renda ou $21,33 \%$ de suas despesas. Para os indivíduos com renda superior a $\mathrm{R} \$$ 3.840 a carga tributária corresponde ao percentual de $17,29 \%$ de sua renda e $26,28 \%$ de suas despesas (PINTOS-PAYERAS, José Adrian. Análise da progressividade da carga tributária sobre a população brasileira. Revista Pesquisa e Planejamento Econômico - PPE. V. 40, no 02. Agosto de 2010. Disponível em http://ppe.ipea.gov.br/index.php/ppe/article/viewFile/1224/1072. Acesso em 21/07/2014., p. 174). 
SILVA BALBÉ, Paulo Valdemar da; BOFF, Salete Oro. O papel do estado e sua política fiscal em um modelo de desenvolvimento sustentável fundado nas garantias e liberdades individuais. Revista Eletrônica Direito e Política, Programa de Pós-Graduação Stricto Sensu em Ciência Jurídica da UNIVALI, Itajaí, v.10, n.3, $2^{\circ}$ quadrimestre de 2015. Disponível em: www.univali.br/direitoepolitica - ISSN 1980-7791

pois o interesse na sua aquisição não se restringe a apenas algumas camadas sociais com determinadas características de poder aquisitivo.

Ademais, os mecanismos adotados são dirigidos somente a uma determinada parcela da população, deixando a descoberto um percentual considerável de indivíduos que, embora não se enquadrem em situação de risco social, não conseguem utilizar os serviços públicos essenciais (saúde, educação) em decorrência de sua precariedade, o que os leva a buscar soluções no mercado, mediante custeio desses bens e serviços com recursos próprios.

Regressividade e desigualdade são, portanto, situações relacionadas. Consequências de um sistema tributário que tem optado pela tributação de renda (principalmente da renda originária do trabalho) e consumo, majorando a pressão fiscal sobre os indivíduos e, consequentemente, diminuindo-lhes as possibilidades de acesso a bens e serviços ${ }^{46}$.

\section{CONSIDERAÇÕES FINAIS}

Desenvolvimento e sustentabilidade são dois termos que somente após a década de 70 passaram a ser utilizados conjuntamente em âmbito global, de modo que a expressão "desenvolvimento sustentável" retrata uma tentativa de síntese de pontos até então divergentes.

O termo "desenvolvimento" foi geralmente associado à visão econômica clássica, traduzido como o ideal a ser alcançado mediante mecanismos e processos de otimização de resultados no livre mercado. Seguindo essa ótica, o incremento dos meios de produção e a liberdade de realização de trocas seriam condições essenciais para que fossem atingidos níveis de riqueza que possibilitassem sua distribuição a todos os indivíduos que compunham a sociedade. Imperioso, com suporte nessa premissa, que se fizesse primeiro o "bolo" crescer, para depois "fatiá-lo".

A sustentabilidade surgiu em um contexto histórico de sérias dúvidas em relação à capacidade de o ambiente continuar como provedor de recursos, ou seja, de

46 GIAMBIAGI, Fábio; ALÉM, Ana Cláudia. Finanças públicas: teoria e prática no Brasil. 4 a. edição. Rio de Janeiro: Elsevier, 2011, p. 253. 
SILVA BALBÉ, Paulo Valdemar da; BOFF, Salete Oro. O papel do estado e sua política fiscal em um modelo de desenvolvimento sustentável fundado nas garantias e liberdades individuais. Revista Eletrônica Direito e Política, Programa de Pós-Graduação Stricto Sensu em Ciência Jurídica da UNIVALI, Itajaí, v.10, n.3, $2^{\circ}$ quadrimestre de 2015. Disponível em: www.univali.br/direitoepolitica - ISSN 1980-7791

matéria-prima, para a crescente industrialização decorrente do aumento do consumo. Sua origem está ancorada na preocupação humana com a possibilidade de manutenção das condições físicas, químicas e biológicas necessárias à continuidade de sua presença no planeta.

Entendeu-se que a conjugação dos termos "desenvolvimento" e "sustentabilidade" levava então a alguns problemas, que bem podem ser expressos nesses dois questionamentos: como se desenvolver (continuar o processo de crescimento econômico) sem esgotar os recursos naturais? Quais seriam as condições ótimas que possibilitassem a "sustentabilidade" (entendida como manutenção do status quo)?

Em resposta a esses questionamentos são inúmeras as alternativas apontadas, originárias de estudos de vários ramos da Ciência, cada um propondo, a seu modo, fazer prevalecer determinadas soluções, condizentes com os dogmas e processos afetos às áreas em que atuam.

O embate entre economistas, biólogos, sociólogos, politólogos, juristas e outros tantos somente passou a adquirir situação de relativo consenso em relação a um ponto específico: de que o tema é relevante e merece aprofundado esforço para sua compreensão, considerando que são fortes as evidências que atestam o processo de declínio das condições ambientais.

Superado o dissenso inicial, caracterizado por posições antagônicas e exclusivistas, atualmente é bastante aceito que o "desenvolvimento sustentável" é um ideal que para sua adequada compreensão se exige um ferramental não afeto exclusivamente a um ramo da Ciência, pois engloba um conjunto de fatores e interrelações de grande complexidade, não possibilitando, a priori, sua redução a um modelo único.

Tem-se buscado, portanto, definir o que é desenvolvimento e o que é sustentabilidade a partir de seus opostos, relacionando-os a Estados-Nação que, de acordo com os dados empíricos identificados como expressivos daquela condição ideal, não tenham atingido patamares mínimos satisfatórios. Identificados esses casos, buscou-se descobrir as supostas causas vinculadas àquelas situações de subdesenvolvimento, para que então fossem propostas soluções relativamente consensuais. 
SILVA BALBÉ, Paulo Valdemar da; BOFF, Salete Oro. O papel do estado e sua política fiscal em um modelo de desenvolvimento sustentável fundado nas garantias e liberdades individuais. Revista Eletrônica Direito e Política, Programa de Pós-Graduação Stricto Sensu em Ciência Jurídica da UNIVALI, Itajaí, v.10, n.3, $2^{\circ}$ quadrimestre de 2015. Disponível em: www.univali.br/direitoepolitica - ISSN 1980-7791

As primeiras tentativas concretas desse tipo de aproximação foram a constatação da pobreza e da desigualdade como fatores condicionantes do subdesenvolvimento, também relacionados (conquanto sem estudos de maior densidade empírica) com a degradação dos recursos naturais. Dessa constatação, decorreram naturalmente tentativas de expressar, em variáveis objetivas, graus ou níveis de desigualdade e pobreza como, por exemplo, o índice Produto Interno Bruto - PIB.

Todavia, a relação inversa entre aumento do PIB e a diminuição da pobreza e desigualdade não resultou comprovada a ponto de se admitir com segurança que o crescimento econômico e o aumento da riqueza sejam condições, por si só, bastantes para o alcance de um estágio de desenvolvimento sustentável. Ademais, novas dúvidas e novas hipóteses surgiram a partir desse impasse.

Um exemplo foi a tentativa de se estipular outros condicionantes para o desenvolvimento que não estivessem diretamente relacionados à riqueza, partindo-se do pressuposto de que os recursos materiais não constituem a finalidade, mas um instrumento para o alcance de um objetivo maior: a liberdade. Logo, seria a liberdade e as capacidades individuais, e não a riqueza, o critério adequado para a aferição do grau de desenvolvimento.

O mercado, conquanto pressuponha certa margem de liberdade nas relações de troca, não pode garantir condições suficientes para a preservação de liberdades substanciais, sequer viabiliza de maneira eficaz meios para a coibição de abusos e prevenção de anomalias dele resultantes, como mostra a história recente do sistema financeiro mundial.

É nesse espaço que deve o Estado atuar como principal regulador e garantidor de liberdades básicas, construindo complexas estruturas e sistemas que tornem possível aos cidadãos o suprimento de suas necessidades primárias, criando condições para o exercício de suas liberdades, especialmente o de fazer escolhas sobre o conjunto de atitudes que poderão ser adotadas para a realização dos propósitos que considerem relevantes para suas vidas.

Utilizando-se da norma como instrumento de sua atuação, o Estado de Direito cria e utiliza sistemas regulatórios voltados ao controle e fiscalização. Estipula balizas à atuação do mercado, propondo padrões de atuação e fiscalizando condutas com o escopo de atingir os objetivos sociais considerados relevantes 
SILVA BALBÉ, Paulo Valdemar da; BOFF, Salete Oro. O papel do estado e sua política fiscal em um modelo de desenvolvimento sustentável fundado nas garantias e liberdades individuais. Revista Eletrônica Direito e Política, Programa de Pós-Graduação Stricto Sensu em Ciência Jurídica da UNIVALI, Itajaí, v.10, n.3, $2^{\circ}$ quadrimestre de 2015. Disponível em: www.univali.br/direitoepolitica - ISSN 1980-7791

pela população durante o processo democrático, ou seja, pelo exercício da soberania popular.

Dentre os objetivos visados, constata-se que a preservação do ambiente e a redução da pobreza e da desigualdade figuram como pautas relevantes nas instâncias políticas formais, usualmente convertidos para a forma legal. Parte-se de uma esfera normativa geral e abstrata, fruto de deliberação pública, para a esfera da concretude dos atos administrativos.

O sistema tributário é constituído nesse processo e é um mecanismo poderoso para a regulação, sendo apto a incentivar padrões de conduta, sob prévia autorização, mediante a aplicação de sanções ou instituição de obrigações pecuniárias. Essa característica ultrapassa o propósito de angariar recursos, ou seja, pode ou não estar pressuposta na criação de uma obrigação fiscal.

Também na função precípua de uma política fiscal, a alocativa de recursos, reside a importância da tributação como meio imprescindível para o custeio da estrutura administrativa e, consequentemente, dos bens e serviços indispensáveis para 0 atendimento das necessidades básicas dos cidadãos (saneamento, saúde, educação, seguridade). Supridas essas necessidades são criadas condições para uma vida digna, dotada de liberdade substancial, capacitando os indivíduos para escolhas em relação àquilo que valorizam.

Pela função redistributiva, procura-se diminuir as diferenças mediante a instituição de critérios de taxação que observem a capacidade contributiva dos cidadãos, sobretudo aqueles com elevada renda, ao mesmo tempo em que são proporcionados mecanismos para a proteção de indivíduos em situação de risco social, este último potencializador de conflitos e criminalidade.

Na observância à capacidade contributiva, principalmente na aplicação do critério da progressividade e na diminuição de uma tributação regressiva, reside a justiça do sistema tributário. As tentativas de realização dessa condição ideal constituem caminho relevante para um acréscimo de legitimidade do Estado e de suas instituições, dando ensejo à melhora nas condições da população, em especial o incremento de sua liberdade substancial, pavimentando caminho para um modelo de desenvolvimento sustentável abrangente, capaz de promover o resguardo do ambiente natural e da espécie humana. 
SILVA BALBÉ, Paulo Valdemar da; BOFF, Salete Oro. O papel do estado e sua política fiscal em um modelo de desenvolvimento sustentável fundado nas garantias e liberdades individuais. Revista Eletrônica Direito e Política, Programa de Pós-Graduação Stricto Sensu em Ciência Jurídica da UNIVALI, Itajaí, v.10, n.3, $2^{\circ}$ quadrimestre de 2015. Disponível em: www.univali.br/direitoepolitica - ISSN 1980-7791

\section{REFERENCIAS DAS FONTES CITADAS}

BOBBIO, Norberto; MATTEUCCI, Nicola; PASQUINO, Gianfranco. Dicionário de Política. Vol. I. Tradução Carmen C. Varriale, Gaetano Lo Mônaco, João Ferreira, Luís Guerreiro Pinto Cacais e Renzo Dini. 11a edição. Brasília: Universidade de Brasília, 1998.

DUTRA, Micaela Dominguez. Capacidade contributiva: análise dos direitos humanos e fundamentais. São Paulo: Saraiva, 2010.

FREITAS, Juarez. Sustentabilidade: direito ao futuro. Belo Horizonte: Fórum, 2011.

GIAMBIAGI, Fábio; ALÉM, Ana Cláudia. Finanças públicas: teoria e prática no Brasil. 4a. edição. Rio de Janeiro: Elsevier, 2011.

KAUL, Inge; GRUNBERG, Isabelle; STERN, Marc A. Bens públicos globais. Tradução de Zaida Maldonado. Rio de Janeiro: Record, 2012.

PINTOS-PAYERAS, José Adrian. Análise da progressividade da carga tributária sobre a população brasileira. Revista Pesquisa e Planejamento Econômico PPE. V. 40, no 02. Agosto de 2010. Disponível em http://ppe.ipea.gov.br/index.php/ppe/article/viewFile/1224/1072. Acesso em $21 / 07 / 2014$.

RAWLS, John. Uma teoria da justiça. Tradução de Jussara Simões. São Paulo: Martins Fontes, 2008.

SACHS, Ignacy. Desenvolvimento: includente, sustentável, sustentado. Rio de Janeiro: Garamond, 2008.

SEN, Amartya. A ideia de justiça. Tradução Denise Bottmann e Ricardo Donidelli Mendes. São Paulo: Companhia das Letras, 2011.

SEN, Amartya. Desenvolvimento como liberdade. Tradução Laura Teixeira Motta. São Paulo: Companhia das Letras, 2010. 
SILVA BALBÉ, Paulo Valdemar da; BOFF, Salete Oro. O papel do estado e sua política fiscal em um modelo de desenvolvimento sustentável fundado nas garantias e liberdades individuais. Revista Eletrônica Direito e Política, Programa de Pós-Graduação Stricto Sensu em Ciência Jurídica da UNIVALI, Itajaí, v.10, n.3, $2^{\circ}$ quadrimestre de 2015. Disponível em: www.univali.br/direitoepolitica - ISSN 1980-7791

TORRES, Heleno Taveira (org). Direito tributário ambiental. São Paulo: Malheiros, 2005.

VEIGA, José Eli da. A desgovernança mundial da sustentabilidade. São Paulo: Editora 34, 2013.

VEIGA, José Eli da. Desenvolvimento sustentável: o desafio do século XXI. $2^{\text {a }}$ edição. Rio de Janeiro: Garamond, 2006.

WEBER, Max. Economia e sociedade: fundamentos da sociologia compreensiva. Volume II. Tradução Regis Barbosa e Karen Elsabe Barbosa. São Paulo: Editora UNB, 1999.

Submetido em: Maio/2015

Aprovado em: Julho/2015 